\title{
Letters
}

All letters are subject to editing and may be shortened. General letters can be sent to bjgpdisclarcgp.org.uk (please include your postal address for publication), and letters responding directly to BJGParticles can be submitted online via eLetters. We regret we cannot notify authors regarding publication.

For submission instructions visit: bjgp.org/letters

\section{Appraisal, wellbeing, and pandemics: why a focus on wellbeing is always warranted}

Doctors are human beings, with personal and professional needs. ${ }^{1}$ Many have spent the pandemic supporting others with little support for themselves. The restart of appraisals offers protected time to have a confidential reflexive conversation with a well-trained peer. The rebalanced 'Appraisal 2020' process $^{2}$ minimises the pre-appraisal paperwork and recognises the impact of the pandemic. We urge doctors to seize this opportunity to make their appraisals valuable and ensure that their investment of time delivers maximum benefit to themselves and their patients.

A focus on wellbeing in appraisal is always warranted. In the World Medical Association Declaration of Geneva, doctors pledge: 'I WILL ATTEND TO my own health, well-being, and abilities in order to provide care of the highest standard. 'A doctor who is unwell cannot give their best care to patients - yet many doctors do not prioritise maintaining their own health and wellbeing. The risk of burnout for doctors was high even before the pandemic. Appraisal, as a process reaching all, is a proactive way to offer a safe place to discuss any concerns and be signposted to resources as needed.

Doctors should understand the code of conduct that defines the limits of professional confidentiality in any setting. If a doctor discloses a risk to personal or patient safety, appropriate action must be taken immediately to protect the vulnerable. An appraisal would be stopped - but so would a casual coffee-room conversation. Sensitive topics are frequently discussed at appraisal without being recorded. The written summary should always be mutually agreed before being signed off. The training for Appraisal 2020 reminds appraisers of this and emphasises the importance of creating a confidential safe space for support.

The core purpose of appraisal is not to revalidate. Appraisal cannot be 'failed'. Its published purposes ${ }^{2,3}$ are clearly supportive and developmental. Most doctors re-license without difficulty by demonstrating their continued competence through appraisal. An absence of concerns has been positively confirmed through appropriate clinical governance but they remain unaware of this aspect of the regulatory process.

Susanne R Caesar,

GP, Academy of Medical Royal Colleges. Email: susi.caesarlanhs.net

Graham Layer,

Consultant General Surgeon, Academy of Medical Royal Colleges.

Stephen Barasi,

Lay representative, Faculty of Medical Leaders and Managers.

\section{Competing interests}

Dr Caesar and Professor Layer are doctors subject to appraisal and revalidation. Dr Caesar was the Chair, Professor Layer the Vice-Chair, and Dr Barasi one of the lay representatives on the Academy of Medical Royal Colleges Professional Development Committee Medical Appraisal 2020 Task and Finish Group, which worked with key stakeholders to define the new process for the restart of appraisals, with a reduction in the required pre-appraisal documentation and a rebalanced focus on support, development, and the wellbeing of doctors in the context of the pandemic.

\section{REFERENCES}

1. McCartney M, Tzortziou Brown V. Appraisal, wellbeing, and pandemics: is a focus on wellbeing now warranted? Br J Gen Pract 2020; DOI: https:// doi.org/10.3399/bjgp20X712697.

2. Academy of Medical Royal Colleges. Medical appraisal guide 2020. London: AoMRC, 2020. https://www.aomrc.org.uk/wp-content/ uploads/2020/09/Medical_appraisal_guide_ covid19 0820.pdf (accessed 10 Nov 2020).

3. NHS Revalidation Support Team. Medical appraisal guide: a guide to medical appraisal for revalidation in England. NHS England, 2013. https://www.england.nhs.uk/revalidation/ wp-content/uploads/sites/10/2014/02/rst-medicalapp-guide-2013.pdf (accessed 10 Nov 2020)

DOI: https://doi.org/10.3399/bjgp20X713585

\section{Appraisal and} revalidation - time for a critical look?

The authors do an excellent job of making us think. ${ }^{1}$ I agree that the annual appraisal session is totally inappropriate for enquiry into general wellbeing etc.

Given that NHS general practice spends a lot of money and time on a process that has never, to my knowledge, been subjected to critical review, might this be a good time to look closely at the effectiveness of appraisal and revalidation?

Declan P Fox,

Semi-retired family physician, Tignish Health Centre, Tignish, Prince Edward Island. Email: declanfoxahotmail.com

\section{Competing interests}

I worked for several years in Canadian general practice and one of my motivators was to escape the evidence-free zone of appraisal and revalidation. I make my views clear to anyone interested in hearing them but have never received any type of monetary reward for that.

\section{REFERENCE}

1. McCartney M, Tzortziou Brown V. Appraisal, wellbeing, and pandemics: is a focus on wellbeing now warranted? Br J Gen Pract 2020; DOI: https:// doi.org/10.3399/bjgp20X712697.

DOI: https://doi.org/10.3399/bjgp20X713597

\section{When is it safe to return to exercise post-COVID-19?}

$A^{\prime}$ Court et al suggest that patients with 'mild' COVID-19 illness, and who are asymptomatic, do not need to restrict exercise. ' While this seems to be a straightforward distinction, new evidence on 'Long COVID' presentations even in patients with 'mild' illness is starting to raise questions on how we define the severity of COVID illness. The National Institute 
for Health Research recently suggested that patients with 'Long COVID' may well represent four subgroups of clinical syndromes, and therefore have different rehabilitation needs. ${ }^{2}$

Often patients report symptoms that are refractory, intermittent, or resolve before returning in episodic bouts (these include (muscle aches, chest pains, dyspnoea, and fatigue), many of which are relative contraindications to exercise. ${ }^{3}$ The reality of COVID is that the clinical course of infection and recovery does not fit clearly defined categories lof mild, moderate, or severe illness) and symptoms rarely fit into the binary category of cardiac or non-cardiac. In addition to this, patients' rehabilitation goals are very individual and often relate to their pre-morbid status, and this requires a tailored approach that takes into account the physical demands of their day-to-day activities and occupation.

Irfan Ahmed,

GP/Sport and Exercise Medicine Registrar, University College London Hospital, London. Email: Irfan.ahmed5anhs.net

Aessa Tumi,

GP ST1 Registrar, St Mary's Hospital, London.

\section{REFERENCES}

1. A'Court C, Shanmuganathan M, Leoni-Moreno JC. COVID-19 and cardiac considerations in the community. Br J Gen Pract 2020; DOI: https://doi. org/10.3399/bjgp20X713141.

2. Mahase E. Long covid could be four different syndromes, review suggests. BMJ 2020; 371: m3981.

3. Nabavi N. Long covid: how to define it and how to manage it. BMJ 2020; 370: m3489.

DOI: https://doi.org/10.3399/bjgp20X713609

\section{Ophthalmia}

\section{neonatorum and the role of primary care}

We thank Maqsood and Mahmood for their article on herpes simplex keratitis in neonates, ${ }^{1}$ which includes pointers on distinguishing HSV keratitis from other infective causes. While this is an interesting clinical point, we feel that it lacks a primary care perspective. 'Sticky eye' is a common presentation in newborns, and is usually due to immature nasolacrimal duct formation, which requires no treatment unless it fails to improve by 1 year of age. Ophthalmia neonatorum, whether bacterial or viral, requires urgent secondary care input for full assessment and treatment. ${ }^{2}$ As discussed in the article by Maqsood and Mahmood, eye infections in the newborn are unlikely to present with features that clearly distinguish benign infections from more significant causes. While the frequency with which HSV causes eye infections in newborns is not stated, we presume that it is uncommon enough that many GPs will not see a case during their career. It is difficult to have a high index of suspicion for such a specific yet infrequently occurring event. We therefore suggest that primary care practitioners need only to distinguish infective from non-infective causes of ocular discharge in neonates, and urgently refer all neonates with suspected infection, while avoiding unnecessary treatment for a newborn with a blocked tear duct.

\section{Douglas GJ McKechnie,}

Academic Clinical Fellow in Primary Care, University College London, London.

Email: douglas.mckechnie.11बuucl.ac.uk

\section{Edward Snelson,}

Consultant in Paediatric Emergency

Medicine, Sheffield Children's NHS

Foundation Trust, Sheffield.

\section{REFERENCES}

1. Maqsood N, Mahmood U. Herpes simplex ophthalmia neonatorum: a sight-threatening diagnosis. Br J Gen Pract 2020; DOI: https://doi. org/10.3399/bjgp20X712973

2. National Institute for Health and Care Excellence. Conjunctivitis - infective: scenario: who should I refer to ophthalmology? 2018. https://cks.nice.org. uk/topics/conjunctivitis-infective/management/ who-should-i-refer-to-ophthalmology/ laccessed 10 Nov 2020)

DOI: https://doi.org/10.3399/bjgp20X713621

\section{A good death is much more than anticipatory drugs}

It is interesting to read Bowers et al's article $^{1}$ as it confirms general practice response in the UK is quite variable as regards end-of-life care. Over a decade ago, the Department of Health published its white paper on End of Life Care Strategy; ${ }^{2}$ in it, four elements were considered (dignity in treatment, adequate symptom control, familiar surroundings, and people).

To achieve 'a good death', having the right conversation is paramount; equally is having adequate coordination among the different professionals looking after the patient, the origin of the Electronic Palliative Care Coordination Systems (EPaCCS) currently in use in different shapes and forms across the UK. ${ }^{3}$ The ability to have early anticipatory drugs as part of advanced care plans shared among organisations (district nursing, out of hours, GPs) is a core element. $^{4-6}$

The question is whether anticipatory drugs are the initial step, as it seems implied in the article, or whether it is the careful discussion with patients and families of the end of the road and the planning of all aspects of care, of sharing information, of required coordination, of support available.

The use of anticipatory drugs should not be discussed in isolation. Understanding the patient's preferences for end-of-life care, including preferred options for the place of care as well as the place of death, and any other personal views, must take place. A coordinated and holistic approach is the only way to achieve a good death.

Pablo Millares Martin,

GP, Whitehall Surgery, Leeds.

Email: pablo.martinanhs.net

\section{REFERENCES}

1. Bowers B, Barclay SS, Pollock K, Barclay S. GPS decisions about prescribing end-of-life anticipatory medications: a qualitative study. $\mathrm{Br} J$ Gen Pract 2020; DOI: https://doi.org/10.3399/bjgp20X712625

2. Department of Health. End of life care strategy: promoting high quality care for adults at the end of their life. London: DH, 2008. https://www.gov. uk/government/publications/end-of-life-carestrategy-promoting-high-quality-care-for-adults at-the-end-of-their-life laccessed 10 Nov 2020).

3. Millares Martin P. Electronic palliative care coordination system (EPaCCS): interoperability is a problem. BMJ Support Palliat Care 2017; 8(3): 358-359

4. Dinnen T, Williams H, Yardley S, et al. Patient safety incidents in advance care planning for serious illness: a mixed-methods analysis. BMJ Support Palliat Care 2019; Epub ahead of print. DOI: 10.1136/bmjspcare-2019-001824

5. Whole Systems Partnership. Independent evaluation of Electronic Palliative Care Co-ordination Systems (EPaCCS) in England. Final report. 2016; https://wnw.thewholesystem co.uk/wp-content/ uploads/2015/11/epaccs_evaluation_report_final_ 